\title{
Análise da leptospirose no estado do Paraná no período de 2010 a 2015
}

\author{
Analysis of leptospirosis in the State of Paraná from 2010 to 2015
}

Análisis de la leptospirosis en el estado del Paraná en el período de 2010 a 2015

\author{
Renan Valério Eduvirgem \\ Doutorando em Geografia, UEM, Brasil \\ georenanvalerio@gmail.com \\ Claudemir Rodrigues Soares \\ Mestrando em Geografia, UEM, Brasil \\ rodrisoaresmi@gmail.com
}

Maria Eugênia Moreira Costa Ferreira Professora Doutora Associada Nível, A, UEM, Brasil eugeniaguart@gmail.com 


\section{INTRODUÇÃO}

O geógrafo que atua no âmbito da geografia da saúde tem papel fundamental nas ciências da saúde, pois utiliza aspectos metodológicos inerente da ciência geográfica, tais como a alta capacidade de cartografar e analisar concomitantemente as questões biológicas, espaciais e sociais (CARVALHO \& SILVA, 2017).

A leptospirose é considerada uma zoonose com maior distribuição mundial (LEVETT, 2001), sendo a mais comum do mundo, sendo ela responsável por 1 milhão de casos graves, com cerca de 60.000 mortes por ano (BOURHY et al. 2017). Essa doença bacteriana em sua forma grave é conhecida como Weil ou mesmo Síndrome de Weil. A causa é fomentada por espiroquetas do gênero Leptospira, na qual inclui 08 espécies patogênicas com pouco mais de 268 sorovares já contabilizados, que podem promover a indução de colonização crônica dos túbulos renais em grande número de animais, não somente com características selvagens, mas também domésticos (FAINE, 1957, FAINE et al. 2000, BARTHI et al. 2003, ADLER \& MOCTEZUMA, 2010).

$O$ veículo de transmissão mais frente é por meio da $\mathrm{H}_{2} \mathrm{O}$, água. Outros meios de contaminação são por: animais infectados, solo contaminado com urina e alimentos (FARR, 1995, BHARTI et al., 2003, EVANGELISTA \& COBURN, 2010). Na Figura 01, podemos observar que os roedores são os principais reservatórios e transmissores dessa zoonose, mesmo que indiretamente.

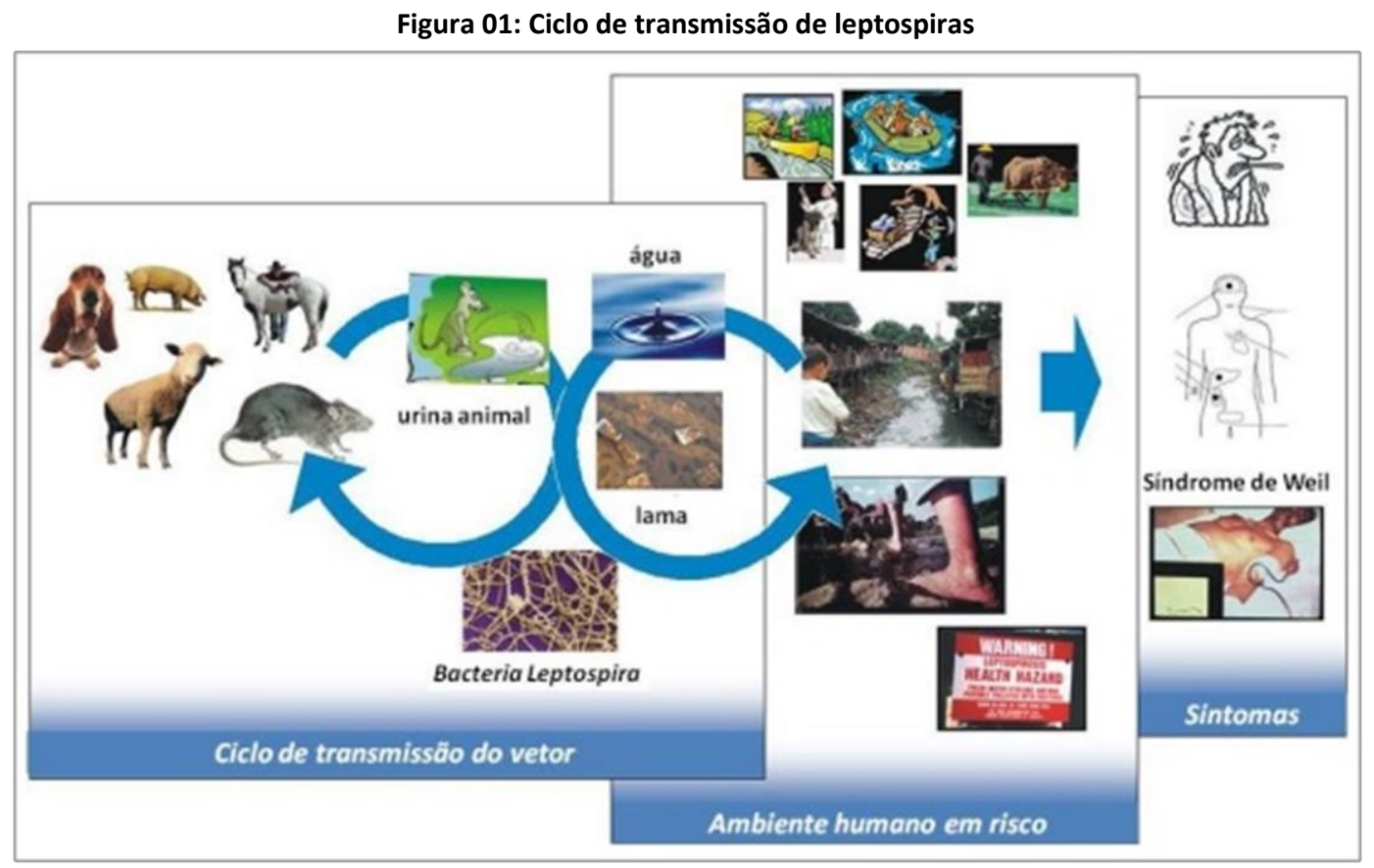

Fonte: BRITO (2010) 
Nos seres humanos, a doença se manifesta de maneiras diversas, tais como: febre, dor de cabeça, mialgia, insuficiência renal, hemorragia pulmonar e icterícia (KO et al., 1999 \& LEVETT, 2001).

De acordo com Tantet et al. (2016), Bouchaud (2018) e Bertholom (2018) a leptospirose é febril e, de fácil ocorrência em áreas tropicais. Essas bactérias são resistentes e podem sobreviver no ambiente por várias semanas, principalmente na água. GUILLOIS, et al. (2017) relatou que as infecções podem ocorrer até mesmo em condições ambientais desfavoráveis para o patógeno, assim, confirmando a resistência e potencialidade de contaminação dessas patologias.

A patologia foi primeiramente descrita por Larrey no ano de 1880, nessa mesma década, Adolf Weil conseguiu descrever a síndrome ictérica em pacientes que apresentavam fenômenos hemorrágicos, nefrite e icterícia.

O tratamento do paciente com essa patologia é realizado por meio de antibióticos (penicilinas e doxiciclina), cujo medicamento reduz as chances da evolução para uma forma mais agravante (BHARTI et al., 2003 \& LEVETT, 2003).

Os maiores índices de casos de leptospirose se concentram nas Caraíbas, Américas Centrais e do Sul, além de casos no Sudoeste da Ásia e Oceania (SANTOS, 2015).

A leptospirose é um problema de saúde pública no Brasil. O período em que há maior disseminação é em períodos de precipitação pluvial, por que em muitas áreas ocorrem alagamentos, e em muitos casos o saneamento básico não se apresenta suficiente. No caso do estado do Paraná os períodos chuvosos diferem, pois o estado possui ampla extensão territorial e, é dominado por dois climas: tropical de altitude e subtropical, o primeiro atua na parte norte do Paraná, até o limite da latitude de $24^{\circ}$, já o segundo dominado a parte central e sul, desse estado. Normalmente no verão, ocorrem os maiores índices de precipitações, no estado do Paraná.

São nos períodos chuvosos que a cautela tem que ser intensificada, pois os riscos de enchentes são maiores. Nhan et al. (2016), afirmam que no período chuvoso e de enchentes há o aumento de casos de leptospirose. Outrossim, os cuidados devem ser mantidos, por que quando ocorre a contaminação dos seres humanos o diagnóstico clínico não é fácil (MONARIS, 2015), pois à variedade de sintomas e, também pelo fato de haver semelhanças à outras doenças tropicais. Entretanto, o diagnóstico pode ser obtido com sucesso por meio de testes sorológicos, com o microscopic agglutination test - MAT - técnica recomendada pela Organização Mundial de Saúde (LEVETT, 2001 \& LEVETT, 2003).

O objetivo desse trabalho é realizar a espacialização dos municípios no estado do Paraná, com casos confirmados de leptospirose no período de 2010 a 2015 e, em seguida realizar o mapeamento de risco de contaminação por leptospirose. $O$ trabalho justifica-se, pois não há mapeamento ao qual realizamos. 


\section{PROCEDIMENTOS METODOLÓGICOS}

Os procedimentos metodológicos foram iniciados por revisão crítica da bibliografia encontrada em livros, periódicos, dissertações e teses, para embasar todo o escopo do trabalho.

A segunda etapa foi pautada no mapeamento da Leptospirose, no estado do Paraná utilizandose de fonte de dados fornecidas pelo DATASUS, cujo obtivemos os dados dos casos confirmados dessa zoonose nos municípios paranaenses.

A terceira e última etapa foi à elaboração de mapas dos munícipios em que mais se apresentou casos confirmados, com o propósito de mapear os municípios que carecem de maiores cuidados por meio da população e dos gestores municipais. Para composição desses mapas, utilizou-se os critérios Alto, Médio a Alto, Médio a Baixo, e Baixo a Nulo. Para a classificação Alto, foram destinados os municípios com mais de 50 casos confirmados, para os Médio a Alto, foram classificados os municípios com casos confirmados inferior a 50 e superior a 10 casos, para a classificação Médio a Baixo, foram os municípios com menos de 10 casos confirmados e mais de 3 casos confirmados, e, para a classificação Baixo a Nulo foram os municípios com 0 a 3 casos confirmados de leptospirose.

Para elaboração dos mapas utilizamos os softwares Quantum GIS 2.18.1, TabWin 414, e o Corel Draw $X 5^{\circledR}$ para finalização dos mapas, prezando a estética dos mesmos, para que o leitor possa compreender com facilidade os dados plotados.

\section{RESULTADOS E DISCUSSÕES}

Ao analisar o ano de 2010, foi possível perceber que o município de Curitiba foi o que registrou 138 casos confirmados de leptospirose. No entanto, os demais municípios despencam nos casos confirmados como Campina Grande do Sul com 17 casos, Londrina 12 casos, Paranaguá 9 casos, Ponta Grossa 7 casos, Araucária 6 casos, São José dos Pinhais 4 casos, e, os demais municípios com casos confirmados variando entre 1 e 3 casos confirmados, com total de 50 municípios com casos confirmados de leptospirose (Figura 02)

Em 2011 houve aumento de municípios com casos confirmados em relação há 2010. No ano de 2011 foram registrados 61 municípios no estado do Paraná com casos confirmados de leptospirose. Curitiba, novamente despontou com o maior número de casos confirmados, com total de 230 casos, seguida por Paranaguá com 42 casos confirmados, Campina Grande do Sul com 30 casos confirmados, São José dos Pinhais com 24 casos confirmados, Campo Largo com 22 casos confirmados, Pinhais com 7 casos confirmados, Fazenda Rio Grande com 7 casos confirmados, Colombo com 7 casos confirmados, Londrina com 6 casos confirmados, Araucária, também com 6 casos confirmados, e Cascavel com 5 casos confirmados. Os demais municípios obtiveram casos confirmados variando entre 1 e 3 (Figura 02).

Ao observar o ano de 2012, é nitidamente possível observar que houve diminuição dos casos espacialmente distribuídos no estado do Paraná. Nesse ano, dos 399 municípios do Paraná, 44 
registraram confirmações de casos de leptospirose. O município de Curitiba novamente foi o que apresentou maior índice de registros de casos confirmados da patologia em análise, todavia, com número reduzido em relação aos anos antecessores, com total de 97 casos confirmados, seguido de Londrina com 13 casos confirmados, Campo Largo com 12 casos confirmados, Ponta Grossa com 11 casos confirmados, Campina Grande do Sul com 10 casos confirmados, Paranaguá com 8 casos confirmados, com 5 casos confirmados foram São José dos Pinhais e Francisco Beltrão, com 4 casos confirmados foi Foz do Iguaçu, e os demais municípios com 1 a 3 casos confirmados (Figura 02).

Em 2013 os números de municípios voltam a aumentar, como é possível observar na Figura 2. De acordo com a espacialização é possível identificar 60 municípios com casos confirmados de leptospirose. O município de Curitiba registrou 148 casos confirmados, Campo Largo com 19 casos confirmados, Campina Grande do Sul com 13 casos confirmados, Londrina com 12 casos confirmados, São José dos Pinhais e Paranaguá com 10 casos confirmados, os municípios de Araucária, Telêmaco Borba e Apucarana, registraram 07 casos confirmados cada, Cascavel com 6 casos confirmados, Santa Izabel do Oeste e Maringá com 5 casos confirmados, Palmeira, Irati e Foz do Iguaçu com 4 casos confirmados cada município, os demais registraram entre 1 e 3 casos confirmados.

Em 2014, foram identificados 60 municípios com casos confirmados de leptospirose. O município de Curitiba foi novamente o munícipio que mais registrou casos confirmados de leptospirose, com total de 118 casos, já São José dos Pinhais e Campo Largo com 12 casos confirmados, Ponta Grossa com 9 casos confirmados, Londrina com 7 casos confirmados, Apucarana com 5 casos confirmados, Toledo, Planalto, Paranaguá, Francisco Beltrão e Campina Grande do Sul com 4 casos confirmados cada, e os demais municípios com variação de 1 a 3 casos confirmados da zoonose em estudo.

Em 2015 o número de municípios volta a aumentar, com total de 84 municípios com casos confirmados de leptospirose. O município de Curitiba registrou 142 casos confirmados, São José dos Pinhais com 19 casos confirmados, Ponta Grossa e Paranaguá com 12 casos confirmados, Campo Largo com 11 casos confirmados, Londrina e Campina Grande do Sul com 10 casos confirmados, Cascavel com 8 casos confirmados, Assaí com 7 casos confirmados, Pinhais com 6 casos confirmados, Jataizinho, Francisco Beltrão, Foz do Iguaçu e Barbosa Ferraz, registraram 5 casos cada município, já Santa Izabel do Oeste, Ivaiporã, Guaraniaçu, Colombo e Araucária, registraram 4 casos cada municípios, e os demais com casos confirmados, obtiveram variação ente 1 e 3 casos (Figura 02). 
Figura 02: Casos de Leptospirose no Paraná, no período de 2010 a 2015

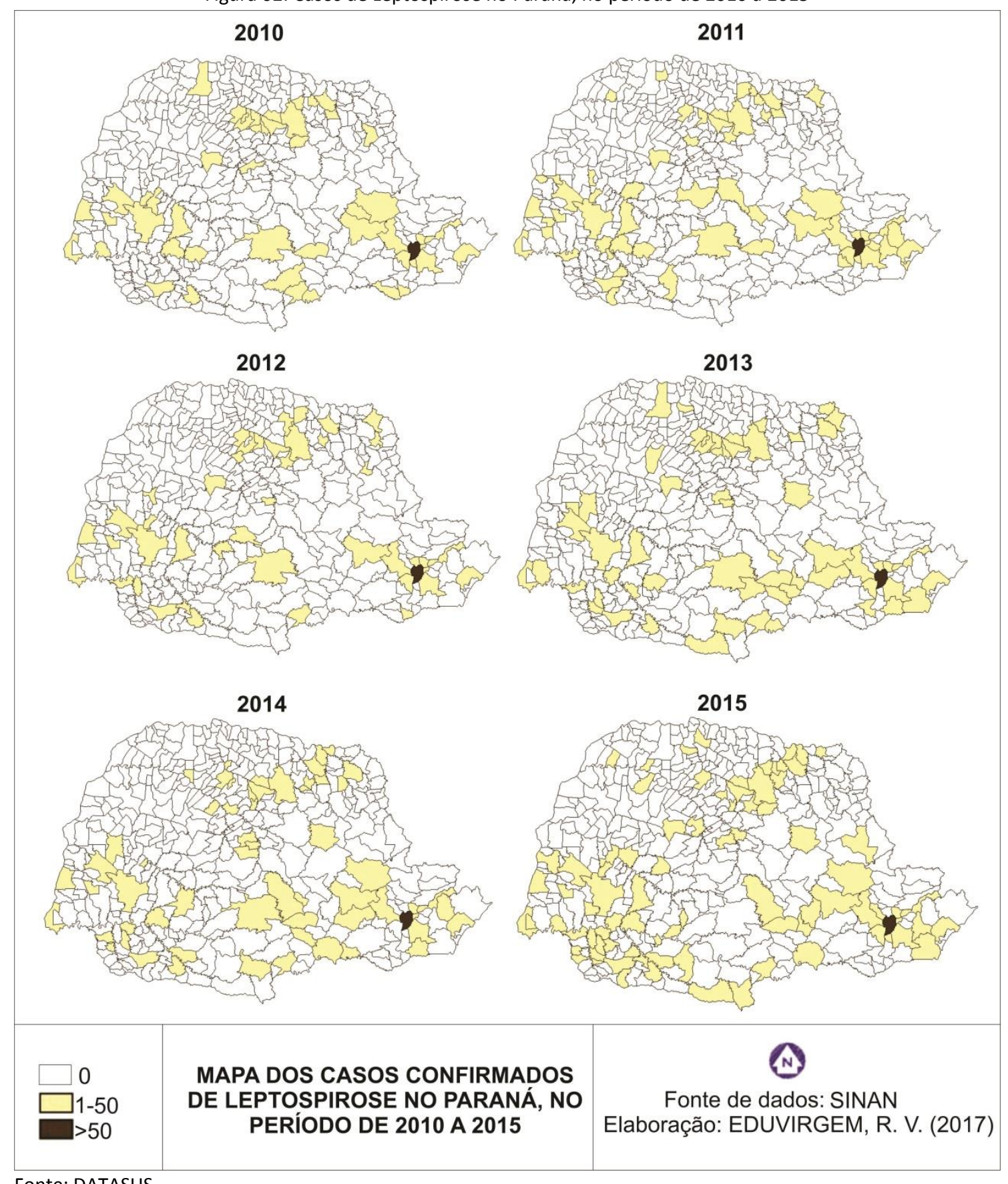

Fonte: DATASUS

Elaboração: EDUVIRGEM, R. V. (2017)

Quanto aos totais de cada ano da série analisada - 2010 a 2015 - pode-se observar na Figura 03. Em 2010 foram registrados 261 casos confirmados, em 2011 foram 473 casos confirmados, em 2012 total de 221 casos confirmados, já em 2013 há novamente o aumento dos casos 


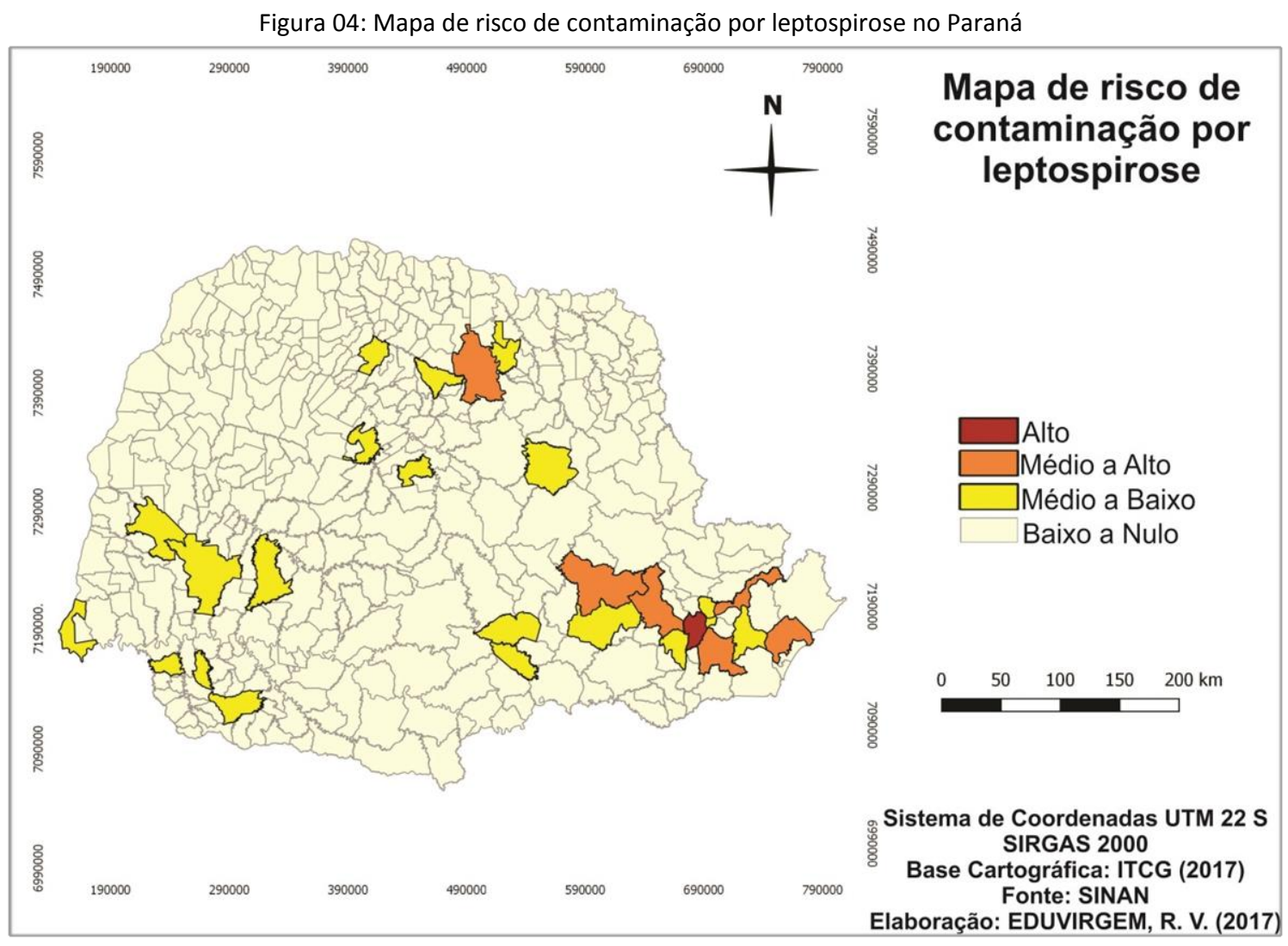

Fonte: SINAN

Elaboração: EDUVIRGEM, R. V. (2017)

A leptospirose no estado do Paraná está presente todos os anos com casos confirmados em diversos municípios. Em com aumento e decréscimo dos casos ano a ano, assim, demostrando a estabilidade da patologia no estado.

\section{CONCLUSÕES}

A leptospirose está presente no estado do Paraná, em diversas partes do estado, demonstrando-se assim, o potencial de disseminação dessa patologia. Entretanto, alguns municípios apresentam mais e outros menos casos confirmados da zoonose.

O mapeamento de risco de contaminação por leptospirose permitiu identificar as áreas e municípios em que foram registrados os maiores valores de casos confirmados da doença. Esse mapeamento pode contribuir para a gestão do estado, no que tange a saúde, por parte dos gestores estaduais e municipais.

Ademais com o mapeamento da patologia pode-se, após identificar situações de risco prevenir e evitar o contato com água sem tratamento adequado ao consumo humano e os locais 


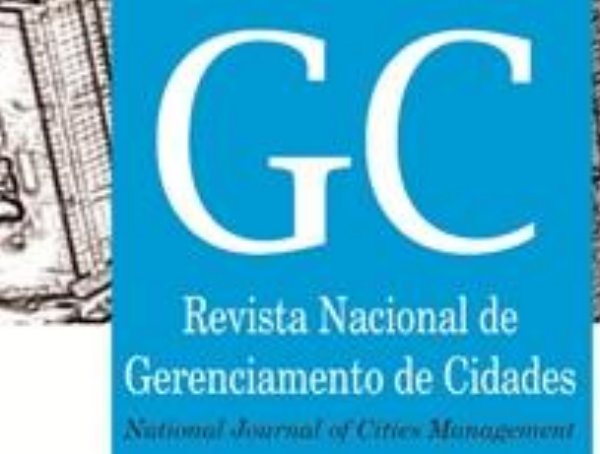

ISSN 2318-8472

possíveis de contaminação pela urina de roedores e, permitir dessa maneira, medidas operacionais de controle de determinados animais transmissor de leptospirose a população.

Os órgãos públicos sejam eles nas esferas municipais, estaduais trabalhando em conjunto e consonância, conscientizando a população, têm papel fundamental para controlar a patologia, determinando a execução de obras de saneamento básico (lixo, esgoto, fornecimento de água e etc...). Contudo outras formas de controle consistem na possibilidade e melhorias em moradias no sítio urbano, essas são atitudes que podem ajudar na prevenção e redução de casos nos municípios mais afetados no estado.

\section{AGRADECIMENTOS}

Agradecimentos a Fundação CAPES pelas bolsas de nível de doutorado e mestrado que permitiram a realização deste estudo.

Agradecimentos também ao Programa de Pós-Graduação em Geografia da Universidade Estadual de Maringá (PGE-UEM) por todo apoio.

\section{REFERÊNCIAS BIBLIOGRÁFICAS}

ADLER, B.; DE LA PEÑA MOCTEZUMA, A. Leptospira and leptospirosis. Vet. Microbiol, v. 140, n. 3-4, p. 287-296. 2010.

BERTHOLOM, C. Diagnostic et épidémiologie de la leptospirose en France. Option/Bio, v. 28, n. 561-562, p. 16-17, 2017.

BHARTI, A. R., NALLY, J. E., RICALDI, J. N., MATTHIAS, M. A., DIAZ, M. M., LOVETT, M. A., LEVETT, P. N., GILMAN, R. H., WILLIG, M. R., GOTUZZO, E. and VINETZ, J. M. Leptospirosis: a zoonotic disease of global importance. Lancet. Infect. Dis., v. 3, p. 757-771, 2003.

BOUCHAUD, O. Fièvre au décours d'un voyage en zone tropicale. Revue Francophone des Laboratoires, v. 2018, n. 500, p. 72-80, 2018.

BOURHY, P. et al. Émergence de la leptospirose humaine en France métropolitaine? Actualités sur la surveillance. Médecine et Maladies Infectieuses, v. 47, n. 4, p. S150, 2017.

BRITO, P. L. Sensoriamento remote na identificação de elementos e tipologias urbanas relacionadas à ocorrência da leptospirose no Subúrbio Ferroviário de Salvador, Bahia. 2010. 258 f. Tese (Doutorado em Engenharia) apresentada a Escola Politécnica, Universidade de São Paulo, São Paulo, 2010.

CARVALHO, M. S.; SILVA, L. F. B. Espacialização das academias ao ar livre na cidade de Londrina-PR: Uma contribuição à geografia da saúde. Hygeia, v. 13, n. 24, p. 1-13, 2017.

EVANGELISTA, K. V.; COBURN, J. Leptospira as na emerging pathogen: a review of its biology, pathogenesis and host imune responses. Future Microbiol, v. 5, n. 9, p. 1413-1425. 2010.

FAINE, S. Virulence in Leptospira. I. Reactions of guinea-pigs to experimental infection with Leptospira icterohaemorrhagiae. Br. J. Exp. Pathol., v. 38, p. 1-7. 1957. 


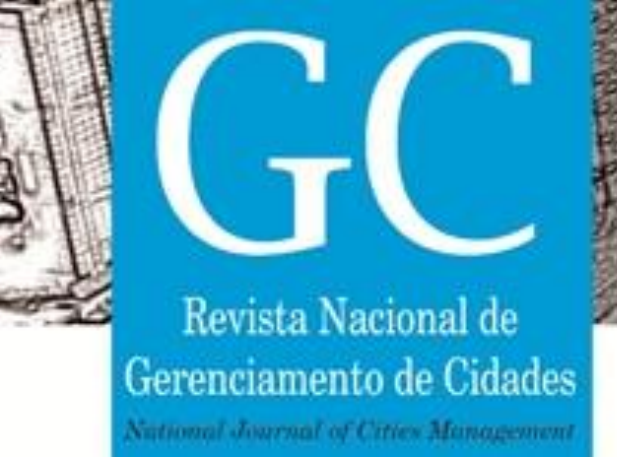

ISSN 2318-8472

FAINE, S.; ADLER, B.; BOLIN, C. and PEROLAT, P. Leptospira and Leptospirosis. 2nd ed. MedSci, Melbourne, Australia. 2000.

FARR, R. W. Leptospirosis. Clin. Infect. Dis., v. 21, p. 1-8. 1995.

GUILLOIS, Y. et al. Cas groupés de leptospirose parmi des kayakistes, Ille-et-Vilaine, 2016. Médecine et Maladies Infectieuses, v. 47, n. 4, p. S114, 2017.

KO, A. I.; GALVAO REIS, M.; RIBEIRO, C. M. D.; JOHNSON, W. D. J. and RILEY, L. W. Urban epidemic of severe leptospirosis in Brazil. Salvador leptospirosis study group. Lancet, v. 354, p. 820-825. 1999.

LEVETT, P.N. Leptospirosis. Clin. Microbiol. Rev., n.14, v. 2, p. 296-326. 2001.

LEVETT, P. N. Usefulness of serologic analysis as a predictor of the infecting serovar in patients with severe leptospirosis. Clin. Infect. Dis., v. 36, p. 447-452. 2003.

MONARIS, D. Avaliação do potencial imunogênico e vacinal das flagelinas de Leptospira interrogans sorovar Copenhageni. 2015. 98 f. Tese (Doutorado em Ciências) apresentada ao Programa de Pós-Graduação em Epidemiologia Experimental Aplicada as Zoonoses da Faculdade de Medicina Veterinária e Zootecnia. Universidade de São Paulo, São Paulo. 2015.

NHAN, Tu-Xuan. et al. Fatal leptospirosis and chikungunya co-infection: Do not forget leptospirosis during chikungunya outbreaks. IDCases, v. 5, p. 12-14, 2016.

SANTOS, L. A. Leptospira interrogans sorovar copenhageni e icterohaemorrhagiae: relação evolutiva, diferenças genéticas e associação com desfecho clínico. 2015. 97 f. Tese (Doutorado em Biotecnologia em Saúde e Medicina Investigativa) apresentada ao Programa de Pós-Graduação em Biotecnologia em Saúde e Medicina Investigativa. Fundação Oswaldo Cruz, Salvador, Bahia. 2015.

TANTET, C. et al. TROP-16-Particularités des formes graves de leptospirose. Medecine et Maladies Infectieuses, v. 4, n. 46, p. 108, 2016. 